Forthcoming in Journal of Eastern African Studies 


\title{
Aid, Trade, and Post-War Recovery of the Rwandan Coffee Sector
}

\author{
Andrea Guariso $^{\dagger}$ \\ Department of Economics, Trinity College Dublin, Dublin, Ireland \\ Marijke Verpoorten ${ }^{\ddagger}$ \\ IOB, University of Antwerp, Antwerp, Belgium
}

January 2018

\begin{abstract}
We investigate the post-war recovery of the Rwandan coffee sector. First, we look at the recovery of export earnings at the national level, and show that the role played by the rise in international coffee prices largely outweighed the one played by domestic policies to boost coffee production and quality. Second, we analyze the subnational variation in the recovery of coffee tree investment, and reveal the legacy of armed conflict. In 1999 - five years after the peak of the violence - highly violence-affected regions exhibit significantly lower tree planting and maintenance. Within a decade, the gap is however closed. We discuss the role that positive externalities generated by high-profile public investments in the coffee sector might have played in the catch-up process. We frame this discussion in the wider debate on the nature of the Rwandan State.
\end{abstract}

Keywords: Rwanda, coffee, armed conflict, trade, aid. JEL: Q18, O13, O55

We thank Elena Briones Alonso, Jean Chrysostome Ngabitsinze, Li Fan, Ameet Morjaria and participants at the Doctoral Workshop at KU Leuven, the CSAE conference in Oxford, and the EABEW conference in Kigali for valuable comments. We benefited from funding of the IOB research fund. Andrea also acknowledges funding from VLADOC (VLIR-UOS) and PODER (EU Marie Curie).

†Trinity College Dublin, Department of Economics, Arts Building, Dublin 2 (Ireland). E-mail: guarisoa@tcd.ie (Corresponding Author) 
‡ IOB Institute for Development Policy and Management, University of Antwerp (UA), Lange Sint Annastraat 7, 2000 Antwerpen (Belgium). E-mail: marijke.verpoorten@ua.ac.be 


\section{Introduction}

In this paper we investigate the evolution of the Rwandan coffee sector after the dramatic cycle of violence that affected the country in the nineties. As we are interested in determinants of post-war recovery, we mainly focus our analysis on the decade 19992009. ${ }^{1}$

Since the turn of the century, Rwanda's real GDP per capita has grown at an average annual rate of $4.7 \%$, more than double the sub-Saharan African average. ${ }^{2}$ Economic growth resulted in a $69 \%$ increase in real GDP per capita over just ten years (1999-2009) and was accompanied by improvements in other measures of economic development: life expectancy rapidly increased from 46.3 in 1999 to 61.8 in 2009 , reaching 66.6 by 2015 , while primary school completion rate more than doubled, moving from $28.8 \%$ in 1999 to $68.4 \%$ in 2009 , before slightly regressing to $60.8 \%$ by $2015^{3}$. Trends in rural growth and poverty indicators were also encouraging, indicating a 5\% average annual growth in the rural sector and a fall in rural headcount poverty from $61.9 \%$ to $48.7 \%$ over the period $2005 / 6-2010 / 11 .^{4}$

This stunning progress came unexpectedly. At the end of the nineties, Rwanda was picking up the pieces of the 1991-94 civil war, the 1994 genocide against Tutsi, and the 1994-98 (counter-)insurgency. Approximately 800,000 Tutsi and politically moderate Hutu were killed in the genocide; and tens of thousands died in the civil war, by revenge killings or during (counter-)insurgency operations. In 1999, millions of refugees who just returned from camps across the border with DR Congo and Tanzania still needed to be resettled; in the Northwest of the country a rural guerrilla campaign was disrupting the economy; hundreds of thousands of prisoners were waiting to be tried; and millions of ordinary people needed to recover from the serious mental and material setback of the war. ${ }^{5}$ In addition, some of the structural factors that were said to have triggered or at least 
intensified the violence, including ethnic polarization and land scarcity, were still in place. $^{6}$

Under these circumstances, several donors and observers expected Rwanda to experience at best slow economic recovery and possibly slide back into violence. This pessimistic expectation was voiced in both academic and policy reports ${ }^{7}$, and was supported by Collier's work on poverty traps. ${ }^{8}$ However, things turned out differently. How did Rwanda manage to escape the vicious circle of conflict and poverty? Some have argued that Rwanda's post-war success story is rooted in the combination of massive foreign aid and technical assistance as well as a complete redesign of the economy by a developmental (authoritarian) state..$^{9}$ As such, the Rwandan government has invested heavily in the promotion of private-sector development by stimulating human capital accumulation through investments in health and education, and by improving public infrastructure and the business environment. ${ }^{10}$ Moreover, the Rwandan State has followed the Washington consensus of liberalizing markets, not the least those of the two most important agricultural export sectors of coffee and tea. ${ }^{11}$ At the same time, however, it has displayed a very direct and active form of market intervention. ${ }^{12}$ Most notably, the ruling political party's holding company 'Crystal Ventures Ltd.', the military investment company 'Horizon', and the public-private consortium 'Rwanda Investment Group' have all directly engaged in private business operations. While some observers claim these operations have distorted competition ${ }^{13}$, others have argued that they have played a pioneering role, especially at early post-conflict times and in sectors in which risk and learning costs where initially too high for ordinary profit-seeking enterprises. ${ }^{14}$ This behavior comes close to the one of early-stage venture capitalist, and is in line with the prescription of Lin and Monga on how a 'facilitative' state can "facilitate structural change by overcoming information and coordination and externality issues". ${ }^{15}$ 
In the polarized debate on the Rwandan State and Rwanda's economic performance, there remain many unanswered questions. Our research contributes to two important, yet largely unanswered ones. First, what is the role that domestic policies played in stimulating Rwanda's impressive growth? Second, is the recovery process shared equally across high and low conflict-intensity regions? It is with these two broad questions in mind that we study the coffee sector in Rwanda.

Although one economic sector cannot be taken as representative for the entire economy, learning about the coffee sector is interesting, both in itself and for gaining insights into the broader development processes in Rwanda. First, the coffee sector is economically very relevant for the country. With an estimated 400,000 coffee farmers ${ }^{16}$, its development has a potentially large effect on rural incomes, employment and poverty reduction; and - being an important source of export revenues - it plays a key role in determining the structural trade balance of the country. Second, the sector's liberalization and its transformation from a supplier of ordinary coffee to a player in the market of specialty coffee fits in the country's broader aim to free up markets and specialize in high value agricultural commodities, while the direct involvement of the Horizon group (in building and managing washing stations) and of Crystal Ventures Ltd. (as majority owner of the Bourbon coffee shops) is exemplary of the direct involvement of politically affiliated actors in Rwanda's economy. Third, the turnaround of the Rwandan coffee sector is widely perceived as a success story, on pair with the impressive national growth figures. Finally, a more practical reason for studying the coffee sector is the availability of unique data from nationwide coffee censuses $\left(1999,2003\right.$ and $\left.2009^{17}\right)$ as well as data on the installation of coffee washing stations ${ }^{18}$, allowing us to trace coffee investments through time and across space. 
Regarding our first research question, we demonstrate that the $37 \%$ rise of Rwandan coffee export earnings over the decade 1999-2009 is mainly driven by world market prices for coffee. Increases in the quantity and quality of coffee produced played only a secondary role. Thus, while the repositioning of the Rwandan coffee sector from a supplier of ordinary coffee to a player in the market for specialty coffee has often been presented as the vehicle for higher prices received by coffee farmers ${ }^{19}$, our findings indicate that its importance is dwarfed by the steep international coffee price rise. Admittedly, one is not independent of the other. In particular, it is possible that, were it not for the domestic policy change, the Rwandan coffee sector could not have ridden the wave of the upturn in the international coffee market. Hence, a subnational analysis may be better suited to evaluate the impact of domestic policies.

In the second part of the paper, we turn to such subnational analysis, and find that post-war investments in the coffee sector vary with conflict intensity, with farmers in heavily affected regions planting less new trees and maintaining existing trees less well up to several years after the conflict (in 1999 and 2003). This finding is consistent with a war overhang effect, which - as described in Collier ${ }^{20}$ - results from the "bad news" of civil war raising perceived uncertainty of future returns on assets, thus discouraging investments. It is also in line with a small number of existing micro-empirical studies that show that violence affects households' behavior and production decisions, often constraining rural households to subsistence farming ${ }^{21}$. Other studies on Rwanda have shown evidence of gaps between low and high conflict intensity areas in terms of household consumption and cattle stock ${ }^{22}$. Since these studies look at a single data point shortly after the end of conflict, little is known, however, on the evolution over time of these gaps: are they closing or widening? Our analysis of the 2009 coffee census data shows that 15 years after the peak of violence, coffee tree investment was similar across 
low and high conflict intensity areas, suggesting that the armed conflict had not caused permanent local poverty traps in coffee investments. We discuss the possibility that the closing of the gap was stimulated by large and highly visible public investments in the coffee sector, that could have acted as 'ice breakers' and helped restoring confidence in coffee production, especially in areas highly affected by the violence.

The rest of the paper is organized as follows. Section 2 dissects the national success story, evaluating the relative role of policies and international coffee prices in the post-war revival of the coffee sector. Section 3 descends to a more disaggregated level, focusing on the subnational variation of coffee tree investment, and how it relates to the spatial pattern of conflict intensity. In Section 4, we provide an empirical framework for estimating this relationship, and present our results. Section 5 concludes.

\section{Dissecting a Success Story}

\subsection{Rise and Fall of the Coffee Sector, 1904-1999}

Coffee was introduced in Rwanda in 1904 by German missionaries. To assure its contribution to government revenue, its cultivation was made compulsory in 1933 by the Belgian rulers; and in 1963 the post-colonial government issued a law that prohibited the uprooting of coffee trees. These coercive measures were complemented with a set of positive stimuli, including the free distribution of seeds and fertilizers and guarantees of stable prices ${ }^{23}$. The coffee was purchased by the Rwandan coffee development authority (OCIR-CAFE) and sold on the international market through two companies called Rwandex and Etiru, in which the government held high capital shares.

This system worked relatively well until the end of the eighties, when the collapse of the International Coffee Agreement brought an end to the worldwide quota system ${ }^{24}$, resulting in a steep fall of coffee prices and a soaring deficit of Rwanda's coffee 
marketing board. Following these events, a liberalization policy was introduced in Rwanda. In 1995, the export market was opened to other exporters besides Rwandex and Etiru; and in 1998 OCIR-CAFE stopped fixing producer prices ${ }^{25}$. While this liberalization policy released farmers from the obligation to produce coffee, it exposed them to fluctuations in world market prices and forced them to rely on private input and output markets. The coffee sector inevitably was also affected by the civil war and genocide in the nineties, as trees were left unattended and access to input and output markets was severely constrained.

The combination of the fall in international coffee prices, the liberalization policy, and the violent conflicts led to a dramatic drop in coffee production. In addition, the quality of the coffee produced was low, resulting in prices below the international reference price, which in turn undermined incentives to invest in coffee production. As a result, farmers uprooted coffee trees and replaced them with food crops or neglected their plantations as the efforts involved in harvesting did not seem warranted ${ }^{26}$. Figure 1 illustrates the steady decline of coffee production in Rwanda in the late eighties and early nineties, from a high of 42,666 tons in 1988 to 27,510 tons in 1993. An all-time low of 1,274 tons was recorded in 1994, the year of the genocide. By 1999, coffee production had considerably recovered although it remained far below its 1980s' level, stabilizing at around 20,000 tons.

- Figure 1 about here -

\subsection{Putting the Sector Back on Track}

After the turn of the century, as a response to the decline in production, in quality and in export earnings and in view of the recognized potential contribution of the coffee sector 
to the economy, the Rwandan government embarked on a strategy of stimulating the production of specialty coffee, a niche product that fetches a higher and more stable price on the world market. This included export tax exemptions for high quality $\operatorname{coffee}^{27}$ as well as close collaboration with donors, NGOs, and private sector to facilitate credit access to coffee investors, especially for the installment of coffee washing stations. ${ }^{28}$ International donors actively supported the government by providing funding, technical assistance and training for the distribution of seedlings and the installation of the stations, and by helping with the launch of an international marketing campaign for Rwandan coffee. For instance, the first significant investment in specialty coffee sector was made possible in 2002 by a $\$ 77,000$ grant provided to Maraba coffee washing station by a USbased NGO supported by USAID. ${ }^{29}$ There was also a direct involvement of politically affiliated actors. As such, the military investment company Horizon built and managed several washing stations ${ }^{30}$, and the Rwandan Patriotic Front's Crystal Ventures Ltd. established Bourbon Coffee, a brand of specialty coffee that has promoted Rwanda coffee on the international scene ${ }^{31}$.

The most impressive and visible aspect of these efforts is the multiplication of coffee washing stations, which increased in number from 2 to 120 in the period 1999 to 2009 and kept growing ever since, to reach 245 in 2015. One of the most important consequences of this multiplication was the reduction in the average distance from a coffee farm to the closest station. This increases the chance that local farmers will bring their coffee to the station. ${ }^{32}$ At the same time, the reduced distance allows for a shorter time between harvesting and processing coffee beans, which is crucial for preserving the quality of the beans. The costs of fully washing coffee are, however, high. It is therefore only rewarding to undertake such process when the final product can enjoy a special price premium on the market, i.e. the premium for specialty coffee. 
This is not always the case: the distinction between semi- and fully-washed coffee does not mirror the difference between ordinary and specialty coffee. The Specialty Coffee Association of America defines specialty coffee as "a coffee that has no defects and has a distinctive character in the cup". In order to obtain such result, it is necessary that all actors involved in the coffee value chain (from the farmer and the casual wage worker, until the retail shop) adhere to the highest quality standards. At the farm level, this implies a careful selection of coffee cherries, excluding defective, immature and overripe cherries. In addition, marketing is an essential part of the specialty coffee business, where origin, social, and environmental certifications are often highlighted. Because of these characteristics, specialty coffee is sometimes referred to as 'relationship coffee', requiring an investment in long-term relations with high-end coffee roasters such as Starbucks, Green Mountain Coffee, Intelligentsia, Wholefoods, and Union Coffee - or with the specialized coffee brokers who buy on their behalf.

An example of a true success story in Rwanda is the Maraba washing station. Built in 2002 with the support of USAID, it is now managed by a farmer cooperative counting over 1,000 members. The origin of every coffee bean that reaches the station is recorded, the nearby laboratory is then used to test its quality, a double register is used to track the provenance of each lot, and farmers receive credits based on the quantity and quality of the beans they provide. Maraba coffee is internationally recognized, having been awarded with the prestigious Cup of Excellence in 2008.

In fact, in the past years, Rwanda has won several awards. On the occasions of winning coffee cupping competitions and new contracts signed, e.g. with Starbucks, popular media have reported on Rwanda's success story. ${ }^{33}$ The sector also received praise from donors. For instance, it is included as an example of a success story in the World Bank publication Yes Africa Can. In this publication, the success is mostly attributed to 
the reforms, in particular the liberalization of the sector and the focus on specialty coffee $^{34}$. Maybe most noteworthy, the transformation is recognized as a success story by one of the world's most well-known aid skeptics, Bill Easterly. Pointing to the role of financial and technical assistance in the revival of the sector, Easterly and Reshef state that "Rwanda's coffee quality upgrade was a foreign aid success despite the usual poor record of aid" 35 . The recovery of the Rwandan coffee sector is thus widely advertised as a success story of government and donor interventions. Looking closer at the data, however, both the success and its attribution to policy need to be qualified.

\subsection{Qualifying the Success}

Figure 1 showed that total coffee production in Rwanda increased from 18,800 tons in 1999 to 19,372 tons in 2009; a modest increase of just $3 \%$. More impressive is that, over the same period, the share of fully washed coffee increased from zero to $19 \%$, and the average price paid for Rwandan coffee increased from $\$ 1.4$ to $\$ 1.9$ or a good $36 \%$. While it is tempting to attribute this price increase to the premium for fully washed coffee, it is actually smaller than the increase in the international coffee price over the same period (from $\$ 2.3$ to $\$ 3.2$ ). ${ }^{36}$ Likewise, while the slight production increase and emerging share of fully-washed coffee certainly contributed to the rise of Rwandan coffee export earnings from $\$ 27$ million in 1999 to $\$ 37$ million in 2009 , their role is dwarfed by the steep international coffee price rise (Figure 2).

\section{- Figure 2 about here -}

Clearly, highlighting the international price increase puts the role of the reforms and the promotion of specialty coffee in perspective. ${ }^{37}$ One of the reasons for the 
relatively small role of specialty coffee in the recovery of export earnings lies in the incomplete transformation of the sector. Despite the rapid multiplication of washing stations, the production of fully washed coffee, which began in 2002, remained far below targeted production. In 2009, its market share reached 19\% (Figure 1), which is quite an achievement, but far below the target (of $60 \%$ ) set in $2002^{38}$. In fact, it is only in 2017 that the production of fully washed coffee passed the $50 \%$ threshold, reaching $52 \%$ of total production. This underachievement can be traced to the large heterogeneity in the performance of the washing stations. Guariso et al. (2012) show that there is a wide variation in capacity use, with some washing stations not being operational at all, others running at full capacity, and an average capacity use of only $29 \%$ in $2009 .{ }^{39}$ The gap between potential capacity and the actual use has been attributed to a mix of factors that include poor management, lack of credit, oversized capacity due to overly optimistic production projections, competition between stations, and lack of a price premium for high quality cherries combined with relatively high market price for ordinary coffee.

Moreover, even in the segment of fully washed Rwandan coffee, not all coffee qualified as specialty coffee and received the mark-up that goes with it. Relying on detailed data on the price paid for all 2007 coffee lots exported, Guariso and coauthors find that the average price for Rwandan fully washed coffee in 2007 was about $\$ 3 / \mathrm{kg}$ (compared to $\$ 2 / \mathrm{kg}$ for ordinary coffee), but the distribution of prices was very skewed, with some lots selling at $\$ 2 / \mathrm{kg}$ and others at more than $8 \$ / \mathrm{kg}$. These very different prices reflect the large variation in the quality of fully-washed coffee produced.

In sum, Rwandan coffee production levels only partially recovered in the postwar years, still staying far below what they were in the heydays of the eighties. Furthermore, in contrast to the image of the home-grow and donor-driven success story, the largest recovery took place in the period well before the promotion of specialty coffee 
(prior to 2000), and thus well before the heavy involvement of donors and the Rwandan government. Moreover, the observed increase in export earnings that took place in the period 1999-2009 was almost entirely due to an increase in world market prices (which, admittedly, would not have reached farmers without the liberalization of the sector). The trends of coffee production and yields in Rwanda over that period are very much in line with the trend in other coffee producing countries (Figures A.1 and A.2 in Appendix), strengthening the argument that the recovery of the pattern was mostly driven by international rather than national factors. While the success story of the Rwandan coffee sector is real, it mostly encompasses a small number of highly performing washing stations that are hardly representative for the sector. Whether the heterogeneous performance of the Rwandan coffee sector relates to conflict exposure is the subject of the next section.

\section{Subnational Variation: the Legacy of Conflict?}

We hypothesize that the within-country variation of coffee sector investments relates to the spatial variation in conflict exposure. In this section we lay out the conceptual framework and our empirical strategy for testing this hypothesis.

\subsection{Conceptual Framework}

In theory, the impact of conflict on post-war investment in the coffee sector may be positive or negative. Two main mechanisms could explain a positive impact. First, there may be a "peace dividend". The peace dividend follows the logic of neoclassical convergence according to which post-war growth is explained by high returns to heavily depleted production factors ${ }^{40}$. It is also in line with what Organski and Kugler termed 'The Phoenix factor' ${ }^{41}$, to describe the rapid rise from the ashes, driven by innovations 
that easily take root in post-war economies. In the case of coffee production, farmers may have been more willing to invest in new and more productive tree varieties if their old coffee trees had been damaged till the point they could not be regenerated. The second mechanism could instead be related to the fact that the donor community as well as the central government might decide to concentrate their efforts to promote (specialty) coffee in conflict-affected regions. ${ }^{42}$

An alternative set of mechanisms could instead explain a negative impact of conflict on coffee investment. First, conflict-affected regions may be characterized by a so-called "war overhang" effect. This is caused by the fact that the occurrence of conflict is "bad news" and while the news of current peace is good, the expected risk of bad news does not fully revert to its pre-war level ${ }^{43}$. This pessimistic outlook on the future might lead individuals in war-affected areas to be more reluctant to engage in investments that are not easily reversible. Second, the capacity to invest may be affected. If war results in a drop in income, then - in the absence of perfect credit markets - total investment may be lower. Moreover, catch-up might take time to materialize, as some production factors, such as human capital (e.g. the knowledge to produce coffee), may be slow to recover ${ }^{44}$.

There are several other channels through which conflict may affect the investment in coffee, by changing its relative attractiveness compared to other crops. These channels relate to five distinctive characteristics of coffee production. First, coffee is a tree crop, requiring a rather large initial sunk cost and with a long gestation period, yielding income only 4 to 5 years after planting. Second, coffee prices tend to fluctuate a lot, causing uncertainty about future returns. Third, unlike many typical subsistence crops, coffee trees need specialized inputs, e.g. the appropriate type and quantity of fertilizer and pesticides. Fourth, coffee is a cash crop that needs to be exchanged on the market. Finally, coffee tree planting and uprooting are traditionally reserved for men. Because of these 
characteristics, any conflict-induced shocks to expectations about the future, time and risk preferences, land tenure security, market and road infrastructure, social capital, labor market and relative endowment of male labor may affect the relative profitability of coffee, thus inducing a reallocation in the investment portfolio of the households.

While with the limited data at our disposal we cannot distinguish between all these various mechanisms, we can test whether areas where the violence was more intense witnessed more or less coffee tree investments at different points in time. In addition, we will probe into the role of investments, studying whether government and donor investments in the coffee sector are related to conflict intensity and with the evolution in coffee tree investments.

\subsection{Econometric Equation}

We investigate the impact of conflict intensity on the coffee sector through a multivariate analysis. Our analysis is based on the following estimating equation:

$$
\mathrm{Y}_{\mathrm{s}, \mathrm{t}}=\alpha \mathrm{C}_{\mathrm{s}}+\Omega \mathrm{X}_{\mathrm{s}}+\Phi \mathrm{T}_{\mathrm{s}}+\mu_{\mathrm{p}}+\varepsilon_{\mathrm{s}, \mathrm{t}}
$$

where $Y$ represents the outcome of interest - farm investment in new coffee trees, maintenance of coffee trees, or the installation of a coffee washing station - in year $t$. The subscript $s$ indicates our unit of analysis, the administrative Sector. The explanatory variable of interest is conflict intensity $C$, while $\varepsilon$ is the error term.

Simply regressing our dependent variable $Y$ on the conflict measure $C$ would run into problems, as reverse causality and omitted variables would likely bias our estimates. We address this issues in three ways. First, we include province fixed effects $\mu_{\mathrm{p}}$ to control for unobserved time-invariant province-level characteristics. Second, we include the vectors $\boldsymbol{X}$ and $\boldsymbol{T}$ to capture coffee growing conditions; $\boldsymbol{X}$ includes Sector-level covariates 
that may explain coffee investment, while $\boldsymbol{T}$ includes proxies for pre-war investment in coffee trees (detailed below). Finally, we run a falsification test showing that conflict intensity does not relate to the number of coffee trees planted prior to the violence, conditional on the controls $\boldsymbol{X}$ and the province fixed effects. More specifically, we estimate the following equation for each one of the proxies for pre-war investment in coffee trees included in the vector $\boldsymbol{T}$ :

$$
\mathrm{T}_{\mathrm{s}}=\beta \mathrm{C}_{\mathrm{s}}+\Gamma \mathrm{X}_{\mathrm{s}}+\pi_{\mathrm{p}}+v_{\mathrm{s}, \mathrm{t}}
$$

\subsection{Data}

\section{The Outcome Variables, $Y$}

Our analysis focuses on three coffee census rounds collected by the Rwandan government in 1999, 2003 and 2009, covering all coffee-producing administrative Sectors of the country. ${ }^{45}$ The 1999 and 2009 datasets record the number of coffee trees in several age groups, while the 2003 dataset provides a rough categorization of the level of tree maintenance. The data - at least for what concerns the 2009 census round - has been recently validated by Mukashema et al, who found a close match between the information in the census and the mapping of coffee obtained through high-definition satellite images $^{46}$.

We use the coffee census data to construct the following outcome variables: number of newly planted (less than 3 years old) coffee trees in 1999; share of very well maintained trees in $2003^{47}$; and number of newly planted trees in 2009 . Panel A of Table 1 reports the summary statistics of these variables. In 1999 there were on average just 43 newly planted trees per $\mathrm{km}^{2}$, compared to 1,014 in 2009 , indicating a sharp increase in new coffee tree investments. ${ }^{48}$ In 2003, the broad categories of tree maintenance indicate 
that one third of the trees were very well maintained, while almost $21 \%$ fell in the category "bad maintenance".

- Table 1 about here -

Figure 3 displays the coverage of the different census rounds and the spatial pattern of coffee tree investment. In Panels A and C darker shaded Sectors indicate a higher density of young trees in 1999 and 2009, respectively. In Panel B, darker shaded Sectors indicate a higher share of very well maintained trees in 2003 . The patterns clearly indicate large heterogeneity in coffee tree investments as well as a substantial increase in investments between 1999 and 2009.

- Figure 3 about here -

In the empirical analysis we need to deal with the administrative reform that took place in Rwanda in 2006. The reform reduced the number of Sectors from 1,536 to 416. The 1999 and 2003 datasets refer to the smaller pre-reform Sectors, while the 2009 dataset considers the larger post-reform ones. To address this challenge, we estimate our empirical model separately for the different rounds. In a robustness check we show that our results are robust to restricting the estimation to the overlapping observations between the census rounds, i.e. to those post-reform Sectors for which all corresponding prereform Sectors were covered in 1999.

\section{Explanatory Variable of Interest, $C$}

Conflict intensity $C$ can be measured in several ways. The Rwandan conflict cycle of the nineties included civil war, genocide, reprisal killings, (counter)insurgency (i.e. rural 
guerilla warfare) and a major refugee crisis ${ }^{49}$. The genocide against Tutsi took by far the largest death toll and has been fairly well documented. Several proxies for genocide intensity exist, such as the pre-genocide share of Tutsi in a Commune ${ }^{50}$, the share of alleged genocide perpetrators in a Sector, and an index of excess mortality derived from two waves of population census data and data from the transitional justice system.

For our main analysis we approximate violence intensity with the 1991 Commune-level share of Tutsi in the population. In Appendix we report the results using three possible alternative measures.

\section{Control Variables, $\boldsymbol{X}$ and $\boldsymbol{T}$}

The vector $\boldsymbol{X}$ consists of several Sector-level covariates likely to be associated with the suitability for coffee growing. These variables capture soil and climatic characteristics, access to market and infrastructures, and land availability. More specifically, the covariates - summarized in Panel C of Table 1 - are: average elevation and standard deviation in elevation (to control for soil unevenness); average 1983-1998 yearly rainfall and average rainfall during the harvest season (March- May); potential coffee yields ${ }^{51}$; number of coffee mills installed by 1960; distance to the closest main road, to the closest main city and to the country border; 1991 population size and total Sector area.

We further control for pre-war investments in coffee trees in the Sector $(\boldsymbol{T})$, by relying on information contained in the 1999 coffee census, which includes the Sectorlevel number of coffee trees in the categories 3-10 years, 10-30 years and more than 30 years. All these trees - with the exception of a small fraction of those aged 3 to $10^{52}$ - were planted before the genocide and therefore provide information about the pre-conflict situation..$^{53}$ 


\section{The Impact of Conflict: Regression Results}

\subsection{Coffee Tree Investment and Maintenance}

Table 2 reports our main results. In the first three columns we look at early post-war coffee tree investment as captured by the (log of the) number of coffee trees that are younger than 3 years in 1999. In the first column we simply control for province fixed effects and cluster the standard errors at the Commune level ${ }^{54}$. The estimated coefficient on the conflict variable indicates that one percentage point more Tutsi in the population in 1991 is associated with 8.4 percent less young trees in 1999 - or 45 less young trees for the average of 535 young trees per Sector.

\section{- Table 2 about here -}

In column (2) we control for the Sector-specific covariates included in the vector $\boldsymbol{X}$. The absolute value of the estimated coefficient slightly decreases to 7.7 percent, but it is now more precisely estimated. In column (3) we add the vector $\boldsymbol{T}$, i.e. the controls for older trees. While significantly increasing the explanatory power of our empirical model and the precision of the estimates, the coefficient of interest remains stable at 8.1 percent. The coefficients on the covariates included in $\boldsymbol{T}$ are all positive and highly significant, indicating that, shortly after the genocide, new investments in coffee trees were more likely in Sectors with a history of coffee production.

In columns (4) and (5) we look at coffee tree maintenance as reported in the 2003 data. We consider the Sector-level proportion of very well maintained trees as the outcome variable. The estimated coefficient on our conflict proxy indicates that a one percentage point increase in the share of Tutsi in 1991 decreases the proportion of trees that are very well maintained in 2003 by about 0.7 percentage points, corresponding to a 
decrease of about $2 \%$ compared to the mean (of 33,3\%). Thus, nine years after the peak of violence, areas more severely affected by the genocide were slightly, but significantly lagging behind in terms of tree maintenance.

Finally, in columns (6) and (7) we focus on the 2009 coffee census. The two columns replicate columns (2) and (3) but now considering trees aged less than 3 in 2009 as the outcome variable, and with all controls re-computed at the level of the larger postreform Sectors. Results no longer show any significant difference between high- and lowconflict intensity areas in the number of newly planted coffee trees. If anything, the coefficient of conflict intensity is now positive. These results indicate a catch-up process fifteen years after the conflict. ${ }^{55}$

\subsection{Falsification test and Robustness Checks}

Lacking a true counterfactual, our claim that the observed relation between coffee investments and conflict intensity is causal relies on the control variables included in the vectors $\boldsymbol{X}$ and $\boldsymbol{T}$. If they do not properly account for Sector-level characteristics that correlate both with coffee production and conflict, our results may be driven by omitted factors. To check for this possibility, we exploit the information on the different age cohorts of trees and run a falsification test. In this test, we regress the number of trees that were planted in the pre-war period (i.e. the old trees aged 3-10, 11-30 and over 30 in 1999) on our conflict measure. Table 3 shows the result of this test, using the same controls as in column (2) of Table $2 .{ }^{56}$ The table clearly indicates that conflict intensity relates negatively only to trees aged 0 to 3 in 1999, not to trees in the older age groups. This makes us confident that omitted variable bias is not a major issue.

- Table 3 about here - 
So far we considered the 1991 share of Tutsi living in the Commune as our measure of conflict intensity. In Appendix we introduce three alternative conflict intensity measures (Tables A.1 and A.2) and we show that our findings are largely confirmed when using any of these alternative measures (Table A.4) ${ }^{57}$ Overall these results confirm that areas more affected by the violence were lagging behind in coffee tree investments five years after the end of the genocide, but no longer fifteen years down the road. ${ }^{58}$

In a final robustness check, we tackle the issue of the 2006 administrative reform. To verify whether the different results across the 1999 and 2009 rounds stem from their coverage of different administrative units, we restrict our sample to the 164 Sectors in the 2009 census for which the corresponding pre-reform Sectors were fully included in the 1999 census. Results are reported in Table 4. The first two columns of the table show that our conclusion for 1999 remains the same: areas more affected by the genocide display a significantly lower number of young trees in 1999. This holds both when we use prereform Sector boundaries (column (1), N=613), and post-reform boundaries (column (2), $\mathrm{N}=164) .{ }^{59}$ In column (3) we report the 2009 results for the subsample of 164 Sectors, which confirms that by 2009 there no longer is any significant difference related to past conflict intensity.

— Table 4 about here -

\subsection{The Role of Investments in Washing Stations}

In section 3.1 we briefly discussed possible ways in which armed conflicts could affect coffee investment decisions. This section empirically explores one of these effects, 
related to donors and government investments. More specifically, we rely on a unique dataset to investigate decisions on the installation of coffee washing stations across Rwanda, and tentatively test for their possible effect on coffee investment decisions.

The rapid rise in the number of washing stations in the period since 2002 was the most visible achievement of the government- and donor-led efforts to put the coffee sector back on track. ${ }^{60}$ In order to understand whether there was an explicit aim to support areas more severely affected by the violence, we exploit information on the location of the new stations. More specifically, we run a set of regressions that are based on the same empirical specification described by model (1), in which we replace the dependent variable with the number of washing stations in the Sector. Information on the stations is obtained from the coffee division of Rwanda's National Agricultural Export Board (NAEB) and is available for the years 2002, 2003, 2005, 2007 and 2008. Columns (1) to (5) of Table 5 report the results for these various years. The estimates clearly indicate that, after controlling for our $\boldsymbol{X}$ and $\boldsymbol{T}$ covariates, the location of washing stations across Sectors did not depend on past conflict intensity.

\section{- Table 5 about here -}

Furthermore, columns (6) to (10) of Table 5 show that the location of washing stations was also unrelated to the level of investments in new coffee trees in the immediate post-conflict period (trees younger than 3 years in 1999). ${ }^{61}$

One particular feature of the coffee washing stations is their great visibility and the fact that they provide an opportunity for coffee farmers to meet each other and with buyers. These characteristics could stimulate coffee tree investment by signaling a serious commitment to coffee production on the part of the government and donors and by 
fostering networking of coffee growers. However, when we look in our data at the change in coffee tree investments over the period 1999-2009 - defined as the difference of (the $\log$ of the) investments in coffee trees between the two census rounds - we do not find any significant association with washing station construction (Table 6, column (2)). ${ }^{62}$ Results in column (3) indicate that a positive relationship only appears for those Sectors that experienced higher conflict intensity. The positive and significant coefficient on the interaction term indicates that for a Sector with a 1991 share of Tutsi equal to 10 percent (the $75^{\text {th }}$ percentile of the distribution in our sample), having a coffee washing station installed by 2007 is associated with a $25 \%$ increase in investment in new coffee trees over the period 1999-2009, compared to a Sector with the same 1991 share of Tutsi that hosts no washing station. ${ }^{63}$ While allegedly this finding is only suggestive of an impact of the washing stations on coffee investments in high-conflict intensity areas, it appears consistent with the idea that the good news (and social interaction) brought by coffee washing stations played a role in stimulating coffee investments in those areas where they were set back by bad news (and mistrust), i.e. by a war overhang effect. ${ }^{64}$ This is also in line with the rich literature on the role of psychological factors as drivers of investment decisions ${ }^{65}$. Thus, even though the washing stations did not lead to the immediate growth of (specialty) coffee production (as discussed in Section 2.3), their rapid multiplication may have helped countering the war overhang effect, encouraging farmers in highconflict intensity areas to invest in coffee trees (and thus allowing them to benefit from the surge in international coffee prices).

- Table 6 about here - 
In sum, the catching up process of investments in new trees materialized somewhere between 1999 and 2009, and thus coincided with the explosion in investments in new coffee washing stations. The location of the stations was independent of conflict exposure and baseline investment in trees. One could hypothesize that this large-scale high-profile indiscriminate investment could be particularly effective in spurring new investments in coffee trees in those areas that were more severely hit by the violence, as the "war overhang" effect was likely more severe there. Although we cannot rule out alternative explanations, we find this to be consistent with the data. Our interpretation is also supported by Elder et al, who find, among other things, that washing stations in Rwanda were particularly successful in stimulating interactions among coffee growers, increasing their level of (inter-ethnic) trust and social capital. ${ }^{66}$

\section{Conclusion}

At the end of the nineties Rwanda was recovering from a horrific genocide, several other forms of violence and a massive refugee crisis. There were many reasons to be pessimistic about Rwanda's future, and expect poverty and conflict to reinforce each other. Yet, in the decade 1999-2009 Rwanda experienced impressive economic growth and development. Some observers attribute the unexpected success to decisive policymaking and - political as well as economic - leadership in Rwanda ${ }^{67}$. Others, analyzing the recovery path using subnational data, highlight the role of a neoclassical catch-up mechanism, i.e. growth seen as a recovery from a post-war low to a (new) steady state growth path. ${ }^{68}$ Both factors likely contributed to the recovery and it seems impossible to tell them apart.

With this paper we dig deeper into the Rwandan recovery through the lens of the coffee sector. The post-war recovery of the coffee sector is largely perceived as a success 
story, and its success is attributed to donor and government policies that freed up markets and enabled the sector to reposition itself as a supplier of specialty coffee. We set out to answer two questions: (1) To what extent can the recovery of the coffee sector be attributed to donor and government policies? (2) To what extent is the recovery path affected by conflict?

Regarding the first question, we showed that the 1999-2009 increases in coffee export revenue and producer prices are mostly driven by increases in the international price of coffee. Admittedly, without the liberalization policy that exposed farmers to world market prices for coffee, much of the international price rise would not have been transmitted to farmers. On the other hand, should the world market prices have decreased, producer prices would have decreased as well. The liberalization policy thus contributed to the recovery of the sector, but conditional on a windfall increase in international coffee prices.

Several commentators have remained silent on this crucial conditionality. Instead, they have attributed the sector's success to policies promoting its liberalization and especially its repositioning from a supplier of ordinary coffee to a supplier of specialty coffee. We showed that, although coffee washing stations have multiplied at an impressive rate, the share of fully washed coffee has remained far below target. These findings underline the need for critically evaluating the data and numbers, and call for caution whenever applauding the transformation of the sector. The findings also speak to the debate on the relative importance of domestic policies versus external factors in explaining the recent African economic growth ${ }^{69}$, siding with the strand of the literature that questions the robustness of the recent growth spurt, qualifying it as being mostly driven by high commodity prices rather than by real structural reforms ${ }^{70}$. 
The finding that internal factors are dwarfed by external factors, does not imply that the formers were unimportant. They could still have played a crucially catalyzing role, without which the Rwandan coffee sector may have been unable to follow the upward international trend. Without a counterfactual, the actual impact of the domestic policies is impossible to establish. We therefore turned to a within-country analysis, for our second research question, trying to unearth whether domestic policies played a role in the post-war catch up of heavily affected areas within Rwanda.

We first showed that the recovery path of the coffee sector is affected by conflict. Our results indicate that investments in new coffee trees and maintenance of existing trees were lagging behind in conflict areas, up to five and nine years after the end of massive violence. Thus, even though national growth figures recovered quickly and impressively once peace was restored, at the subnational level we find indications of a war overhang effect that lingered on for at least a decade. However, similarly to what Miguel and Roland find in the context of Vietnam ${ }^{71}$, we observe no long-lasting local poverty traps. Fifteen years down the road there are clear signs of catch-up: by 2009, farmers in heavily affected areas invested no less in new trees compared to farmers in less affected areas.

We mentioned different mechanisms that could explain this time-path of recovery. While we did not have the data to estimate the contribution of each one of them, we explored more in detail the signaling effect hypothesis. We did not find any evidence that the construction of new coffee washing stations especially targeted conflict-affected regions and we found no indication of any overall positive relationship between the presence of washing stations and the evolution of coffee tree investments over the 19992009 period. Washing station installment, however, did relate positively to the evolution of coffee tree investment in areas more severely affected by the violence. 
Thus, while the promotion of specialty coffee may not have contributed much to the overall rise in coffee production, it may have contributed to the post-war micro-level catch-up process by affecting expectations and/or human relations and thereby farm investments in coffee trees. Although this aligns well with recent research on the role of washing stations in building trust in Rwanda ${ }^{72}$, the bad news/good news hypothesis needs further investigation. If confirmed, it would imply that the signaling function of policies in post-war settings is crucially important to counter a war overhang effect. 


\section{Bibliography}

African Development Bank. 2013. Situational Analysis of the Reliability of Economic Statistics in Africa: Special Focus on GDP Measurement.

Ansoms, A., Marijnen, E., Cioffo, G., and J. Murison. 2017. Statistics versus livelihoods: questioning Rwanda's pathway out of poverty. Review Of African Political Economy. 44(151): 47-65.

Arbache, J. S. and J. Page. 2010. How Fragile Is Africa's Recent Growth? Journal of African Economies. 19 (1): 1-24.

Barro, R.J. and X. Sala-i-Martin. 2004. Economic Growth. 2nd ed. Cambridge, MA: MIT Press.

Basinga, P., Gertler, P.J., Binagwaho, A., Soucat, A.L.B., Sturdy, J.R., and C.M.J. Vermeesch. 2010. Paying Primary Health Care Centers for Performance in Rwanda. World Bank Policy Research Working Paper No. 5190.

Behuria, P. 2016. Centralising rents and dispersing power while pursuing development? Exploring the strategic uses of military firms in Rwanda. Review of African Political Economy. 43 (150): 630-647.

Behuria, P. and T. Goodfellow. 2016. The political settlement and 'deals environment' in Rwanda: Unpacking two decades of economic growth. ESID Working Paper No. 57. Manchester, UK: The University of Manchester.

Booth, D. and F. Golooba-Mutebi. 2012. Developmental patrimonialism? The case of Rwanda. African Affairs. 111 (444): 379-403.

Boudreaux, K. C. 2011. Economic Liberalization in Rwanda's Coffee Sector: A Better Brew for Success. Chapter 14 in Yes Africa Can: Success stories from a dynamic continent. World Bank, Washington DC.

Brück, T. 2006. War and reconstruction in northern Mozambique. Economics of Peace and Security Journal. 1 (1): 30-39.

Chunan-Pole, P. and M. Angwafo. 2011. Yes Africa Can: Success stories from a dynamic continent. World Bank, Washington DC.

Clay, D.C. 1996. Fighting an Uphill Battle: Population Pressure and Declining Land Productivity in Rwanda. MSU International Development Working Paper 58. Department of Agricultural Economics, Michigan State University.

Collier, P. 1999. On the economic consequences of civil war. Oxford Economic Papers. 51 (1): 168-183.

Collier, P. 2007. The Bottom Billion: Why the Poorest Countries are Failing and What Can Be Done About It. Oxford University Press. 
Des Forges, A. 1999. Leave None to Tell the Story. Human Rights Watch, New York, NY.

Easterly, W. and A. Reshef. 2010. African export successes: surprises, stylized facts and explanations. NBER Working Paper No. 16597.

Elder, S. D., Zerriffi, H., and P. Le Billon. 2012. Effects of Fair Trade Certification on Social Capital: The Case of Rwandan Coffee Producers. World Development. 40 (11): 2355-2367.

Ghura, D. 1995. External Forces, and Economic Growth in Sub-Saharan Africa. Economic Development and Cultural Change. 43 (4): 759-778.

Gökgür, N. 2012. Rwanda's Ruling-party Owned Enterprises: Do they Enhance or Impede Development? Antwerp: Institute of Development Policy and Management (IOB) Discussion Paper.

González, M.A. and R. Lopez. 2007. Political Violence and Farm Household Efficiency in Colombia. Economic Development and Cultural Change. 55 (2): 367-92.

Guariso, A., Ngabitsinze, C. J., and M. Verpoorten. 2012. The Rwandan Coffee Sector: out of the Ordinary, in: Reyntjens F., Vandeginste S., et Verpoorten M. (eds.) L'Afrique des grands lacs. Annuaire 2011-2012, Paris, L'Harmattan: 397-426.

Heldring L. 2014. State Capacity and Violence: Evidence from the Rwandan genocide. CSAE Working Paper WPS 2014-08.

Lin, J. Y. and C. Monga. 2011. Growth identification and facilitation : the role of the state in the dynamics of structural change. Policy Research Working Paper Series 5313, The World Bank.

Loveridge, S., Nyarwaya, J. B. and E. Shingiro. 2003. Decaffeinated? Situation, Trends, and Prospects for Coffee Production in Rwanda. Rwanda Food Security. Number $5 \mathrm{E}$.

Macchiavello, R. and A. Morjaria. 2017. Competition and Relational Contracts: Evidence from Rwanda's Coffee Mills. Mimeo.

Mann, L. and M. Berry (2016). Understanding the Political Motivations That Shape Rwanda's Emergent Developmental State. New Political Economy. 21 (1): 119144.

Miguel, E. and G. Roland. 2011. The long-run impact of bombing Vietnam. Journal of Development Economics. 96: 1-15.

Minten, B., Dereje, M., Engida, E., Kuma, T. 2017. Coffee value chains on the move: Evidence in Ethiopia. Food Policy, forthcoming.

Mukashema, A., Veldkamp, A. and A. Vrieling. 2014. Automated high resolution mapping of coffee in Rwanda using an expert Bayesian network. International Journal of Applied Earth Observation and Geoinformation. 33: 331-340. 
Murezeki, A., Songqing, J. and S. Loveridge. 2014. Have coffee producers benefited from the new domestic cherry market? Evidence using panel data from Rwanda. Agricultural Economics. 45 (4): 1-12.

Olakojo, S. A. 2015. Export Commodity Prices and Long-Run Growth of Primary Commodities-Based African Economies. CSEA Working Paper WPS/15/02.

Organski, A.F.K. and J. Kugler. 1977. The Costs of Major Wars: The Phoenix Factor. The American Political Science Review. 71 (4): 1347-1366.

Republic of Rwanda. 2000. Vision 2020. Published by the Ministry of Finance and Economic Planning.

Republic of Rwanda. 2008. Rwanda Coffee Strategy Update 2009-2012. Ministry of Agriculture \& Animal Husbandry and Ministry of Trade \& Industry.

Republic of Rwanda. 2012. The evolution of poverty in Rwanda from 2000 to 2011: results from the household surveys (EICV). Published by the National Institute of Statistics.

ROAPE (Review of African Political Economy). 2017. Rwandan Poverty Statistics: Exposing the 'Donor Darling'. Blogpost.

Schilling, M. and T. McConnell. 2006. Model for Siting Coffee Washing Stations in Rwanda. Mimeo.

Serneels, P. and M. Verpoorten. 2015. The Impact of Armed Conflict on Economic Performance: Evidence from Rwanda. Journal of Conflict Resolution. 59(4): 555592.

Tardif-Douglin, D., Ngirumwami, J.-L., Shaffer, J., Murekezi, A., and T. Kampayana. 1996. Finding the Balance Between Agricultural and Trade Policy: Rwanda Coffee Policy in Flux. Michigan State University, Food Security International Development Working Papers 54691.

Tuckett, D. 2011. Minding the Markets - An Emotional Finance View of Financial Instability. Palgrave Macmillan, UK.

USAID. 2006. Assessing USAID's investments in Rwanda's coffee sector: Best practices and lessons learned to consolidate results and expand impact. USAID/Chemonics International Inc.

Verpoorten, M. 2009. Household coping in war- and peacetime: Cattle sales in Rwanda, 1991- 2001. Journal of Development Economics. 88 (1): 67-86.

Verpoorten, M. 2012a. Detecting hidden violence: The spatial distribution of excess mortality in Rwanda. Political Geography. 31 (1): 44-56.

Verpoorten, M. 2012b. Leave none to claim the land A Malthusian catastrophe in Rwanda? Journal of Peace Research. 49 (4): 547-563. 
World Bank. 1998. Rwanda - Country Assistance Strategy (English). Washington, DC: World Bank.

World Bank. 2017. World Development Indicators. (accessed February 6, 2018) https://data.worldbank.org/indicator. 
${ }^{1}$ Although we focus on the period 1999-2009, we provide more recent figures when relevant, and show in Appendix that our results remain qualitatively the same when we extend the analysis to more recent years.

${ }^{2}$ World Bank, World Development Indicators.

${ }^{3}$ Ibid.

${ }^{4}$ Republic of Rwanda, The evolution of poverty. It should be mentioned that the accuracy of Rwandan administrative data, particularly in relation to poverty figures, has been questioned (Ansoms et al, Statistics versus livelihoods; ROAPE, Rwandan Poverty Statistics). According to the African Development Bank, Rwanda ranks 28th in terms of overall quality of its national accounts, over a list of 44 African countries (ADB, Situational Analysis).

${ }^{5}$ Des Forges, Leave None; Verpoorten, Detecting hidden violence, 44-56.

${ }^{6}$ Verpoorten, Leave none, 547-563.

${ }^{7}$ see Clay, Fighting an Uphill, and, World Bank, Rwanda - Country Assistance Strategy.

${ }^{8}$ Collier, The Bottom Billion. Rwanda qualifies for at least two of Collier's poverty traps: the experience of the civil war and the a landlocked location surrounded by conflict-prone poor economies.

9 Booth and Golooba-Mutebi, Developmental patrimonialism?, 379-403; Mann and Berry, Understanding the Political, 119-144.

${ }^{10}$ Basinga et al., Paying Primary.

${ }^{11}$ Republic of Rwanda, Vision 2020.

${ }^{12}$ See note 9.

${ }^{13}$ Gökgür, Rwanda's Ruling-party.

${ }^{14}$ See note 9.

${ }^{15}$ Lin and Monga, Growth identification.

${ }^{16}$ USAID, Assessing USAID.

${ }^{17}$ Our analysis focuses on the first decade of the new century, immediately following the end of the conflict cycle. A new coffee census was collected in 2015 and results are confirmed whenever including that census in the analysis. We report the results in Appendix.

${ }^{18}$ Coffee washing stations are facilities that use spring water to remove the fruity pulp from the coffee cherries, separating out the beans that are then dried and stored for marketing. The process is semi-automated, and allows for several quality control methods to be employed to sort the coffee into various grades.

${ }^{19}$ Boudreaux, Economic Liberalization; Chunan-Pole and Angwafo, Yes Africa.

${ }^{20}$ Collier, On the economic, 168-183.

${ }^{21}$ e.g. Brück, War and reconstruction, 30-39; González and Lopez, Political Violence, 367-92.

${ }^{22}$ Serneels and Verpoorten, The Impact, 555-592; Verpoorten, Household coping, 67-86. 
${ }^{23}$ Tardif-Douglin et al., Finding the Balance.

${ }^{24}$ The International Coffee Agreement signed in 1983 established a system of export quotas to secure price stability within ranges agreed upon annually by exporting and importing members.

${ }^{25}$ Ibid.

${ }^{26}$ Loveridge et al., Decaffeinated? Situation.

${ }^{27}$ Murezeki et al, Have coffee, 1-12.

${ }^{28}$ Boudreaux, Economic Liberalization.

${ }^{29}$ See note 16.

${ }^{30}$ In 2007 - the year for which we have the most detailed information - there were still 12 washing stations owned directly by the Horizon group or by para-statal entities.

${ }^{31}$ Behuria, Centralising rents, 630-647; Behuria and Goodfellow, The political settlement; Gökgür, Rwanda's Ruling-party.

${ }^{32}$ Within the context of coffee production in Ethiopia, Minten et al (Coffee value) find that farm distance plays a key role in determining whether farmers will bring their beans to a wet or dry mill.

${ }^{33}$ One of many examples is the article by L. Fraser titled "Coffee, and Hope, Grow in Rwanda", New York Times, August 6, 2006.

${ }^{34}$ Chunan-Pole and Angwafo, Yes Africa.

${ }^{35}$ Easterly and Reshef, African export, 4.

${ }^{36}$ The figures are taken from the World Bank database and refer to the international price for Arabica coffee, which is the predominant variety in Rwanda. Alternative sources provide similar figures: from $\$ 2.2$ to $\$ 3.1$ based on the New York Coffee Price Index for fully-washed Arabica coffee, and from $\$ 2.3$ to $\$ 2.9$ based on the international coffee prices published by the International Coffee Organization (ICO).

${ }^{37}$ The role of the international coffee price rise is often ignored. For instance, looking at the period 2003-2008, the World Bank publication Yes Africa Can highlights that the average export price of Rwandan green coffee increased from $\$ 1.60$ to $\$ 3.10$ (94\%), but it fails to mention that the world market price for coffee rose from $\$ 1.41$ to $\$ 3.06$ (117\%) over the same period.

${ }^{38}$ Republic of Rwanda, Rwanda Coffee.

${ }^{39}$ See also Macchiavello and Morjaria, Competition and Relational.

${ }^{40}$ Barro and Sala-i-Martin, Economic Growth.

${ }^{41}$ Organski, and Kugler, The Costs, 1347-1366.

${ }^{42}$ According to the World Bank, the amount of aid received by Rwanda in 1999 was close to the pre-1994 levels, at roughly 550 million (in constant 2013 US\$). However, it almost doubled between 1999 and 2009, reaching 990 million. While with the data at our disposal it is impossible to identify which areas benefited the most, conflict-affected regions benefited from a number of specific programs. Within the educational sector, for instance, the largest program was the FARG 
(Fonds d'Assistance aux Rescapés du Génocide), which awarded scholarships for secondary schooling to genocide survivors. A nationally representative survey collected in 2000 indicates that less than $5 \%$ of the students enjoyed a scholarship in the Northern Provinces (where few Tutsi lived), compared to more than $12 \%$ in some of the Central and Southern Provinces.

${ }^{43}$ See note 2 .

${ }^{44}$ See note 40.

${ }^{45}$ A new coffee census round was collected in 2015 . The results obtained using this latest round are in line with those obtained using the 2009 dataset and are reported in Appendix.

${ }^{46}$ Mukashema, et al, Automated high, 331-340.

${ }^{47}$ The criteria for the categorization are not specified, but they most probably include best practices such as pruning, mulching, weeding, and the usage of pesticides.

${ }^{48}$ The values are computed dividing the average number of trees per Sector (535 and 53,047, respectively for 1999 and 2009) by the average size of the old and new administrative Sectors (12.41 and $52.29 \mathrm{~km}^{2}$, respectively).

${ }^{49}$ Verpoorten, Detecting hidden, 44-56.

${ }^{50}$ Commune indicates the administrative level above the Sector. There were 154 Communes in Rwanda before the administrative reform.

${ }^{51}$ We proxy potential yield with information on the expected yield of very well maintained trees, as recorded in the 2003 census.

${ }^{52}$ We repeated all estimations excluding the category 3-10 years from the controls and results remained qualitatively unchanged (results available on requests).

${ }^{53}$ Coffee trees may have been uprooted during the conflict, or in the immediate post-war years. In this case, the number of trees older than 3 years as recorded in the 1999 census would be an underestimation of the true number of trees that were planted before the conflict. If more trees were uprooted in the more affected areas, the underestimation would be related to conflict intensity and thus bias our coefficient of interest. There is no indication that the uprooting of coffee trees occurred on a large scale during the violence. In fact, in some cases the local administration explicitly established that all crops standing on the fields of killed people were to belong to the Commune and were to be protected by the people of the Sector in which they were located (Des Forges, 1999). An additional piece of evidence is provided by our robustness test reported in Table 3, which shows that genocide intensity is unrelated to the number of old trees recorded in the 1999 census.

${ }^{54}$ The 1999 and 2003 samples include 78 Communes, while the 2009 sample includes 134 Communes.

55 Table A.3 in Appendix shows that the result is confirmed when looking at the 2015 coffee census. 
${ }^{56}$ Table 3 as well as all the following tables only display the coefficients of interest. The full tables are available on request.

${ }^{57}$ Figure A.3 shows the coverage and geographic distribution of the different conflict variables.

58 Tables A.5 to A.10 in Appendix replicate all our additional tables using the three alternative conflict measures.

${ }^{59}$ All the controls are re-computed according to the different boundaries.

${ }^{60}$ While there are today also a large number of privately owned washing stations in Rwanda, donors (especially USAID) and the Rwandan government initiated the wave of investments in the coffee sector (for more details, see Schilling and McConnell (Model for Siting) and USAID (Assessing USAID)). Other efforts included investments in seeds development, agricultural extension practices, the stimulation of cooperatives, and the sponsorship of international partnerships with large coffee traders.

${ }^{61}$ The lack of an association between the placement of washing stations and conflict intensity is in line with Schilling and McConnell (Model for Siting), who describe the criteria for the locational choice as based on the suitability of the region to coffee growing, the presence of good transportation roads, the presence of plentiful clean water, the absence of other washing stations in the same service area, the availability of land for the construction of the station, and the absence of a national park in the nearby area (see also Macchiavello and Morjaria, Competition and Relational).

${ }^{62}$ We consider the presence of washing stations in 2007 because the dependent variables equal coffee trees younger than 3 years by 2009, which were therefore planted from 2007 onwards. Using the presence of washing stations in 2008 delivers in any case similar results.

${ }^{63}$ This was obtained by computing (exp $\left.(-0.639+0.086 * 10)-1\right) \%$. The positive effect of the washing station is for Sectors with a share of Tutsi greater than 7.4\% (0.639/0.086). The average change in (the log of) investments in coffee trees is equal to $6.89 \%$.

${ }^{64}$ Further supporting this interpretation is the fact that the interaction term between the presence of a washing stations and the intensity of the violence, if anything becomes negative when looking at the evolution in coffee trees investments between 2009 and 2015 (Table A.11, in Appendix). This confirms that the signaling value of the washing station played a role in restoring confidence only in the aftermath of the violence, when uncertainty was likely higher.

${ }^{65}$ See for instance Tuckett, Minding the Markets.

${ }^{66}$ Elder, et al, Effects of Fair, 2355-2367.

${ }^{67}$ See note 9 .

${ }^{68}$ Serneels and Verpoorten, The Impact, 555-592.

${ }^{69}$ See Ghura, External Forces, 759-778.

${ }^{70}$ Arbache and Page, How Fragile; Olakojo, Export Commodity.

${ }^{71}$ Miguel and Roland. The long-run. 
${ }^{72}$ Boudreaux, Economic Liberalization; Elder et al, Effects of Fair. 